\title{
Trends in Comprehensive Abortion Care (CAC) and characteristics of women receiving abortion care in a tertiary hospital in Nepal
}

\author{
Jamuna Tamrakar Sayami®
}

\begin{abstract}
Background: One of the leading cause of maternal mortality and morbidity is unsafe abortion. Globally 55.7 million of abortions occurred each year between 2010 and 2014. In lower resource countries 24.3 million abortions were unsafe which is significantly higher. Nepal is one of the lower resource countries among others. Comprehensive abortion care (CAC) service can reduce this burden among women.

Methods: A retrospective review of CAC service register at Tribhuvan University Teaching Hospital (TUTH) was conducted to collect data from 2006 to2015 with approval from the Nursing Department to identify the trends of CAC service delivery, client characteristics, category of service providers, and reason for seeking CAC services, its effectiveness and complications. The data was entered in SPSS software and descriptive analysis was performed.

Results: A total of 2367 women received CAC in ten years period showing similar trend as 272-275 cases per year. Women's mean age was 28.4 years, 34\% attained secondary level education and $98.9 \%$ were married. $70 \%$ were house wives and $84 \%$ multi gravid. The gestational period varied from 5 to 12 weeks. $85.6 \%$ had Manual Vacuum Aspiration (MVA) and 14.4\% had Medical Abortion (MA). Only 37.6\% women used any method of post abortion contraception. Unwanted pregnancy was the commonest reason for CAC. A majority of service providers were doctors (62.4\%). The nurses were equally competent to provide CAC service as doctors.
\end{abstract}

Conclusions: The number of women receiving CAC was relatively constant over the ten-year period. Nurses should be promoted for providing CAC services to cover a larger population in need.

Keywords: Comprehensive abortion care, Manual vacuum aspiration, Medical abortion, Post abortion care

\section{Background}

Globally 55.7 million abortions occurred each year between 2010 and 2014. In low-resource countries, 78.2\% of abortions are unsafe, compared to $17.8 \%$ in high-resource countries [1]. There was a sharp decline in maternal mortality, which fell from 580 maternal death per 100,000 live births in 1995 to 190 per 100,000 in 2013 with the abortion legalization [2]. In 2014 about 137,000 legal abortions were provided in Nepal. Public facilities provided $37,34 \%$ by

Correspondence: jamunats10@gmail.com

Cardio Thoracic Vascular and Transplant Center (MCTVC), Tribhuvan University Teaching Hospital Complex, Institute of Medicine, Tribhuvan University, Maharajgunj, Kathmandu, Nepal
NGO facilities and $29 \%$ by private facilities. In 2014 an estimated 80,500 women were treated in health facilities for complications of miscarriage or induced abortion. Among the facilities providing post abortion care, the largest proportion was covered by the private sector [3]. In Nepal nearly $80 \%$ of maternal mortality was due to direct causes and out of which $13 \%$ were due to unsafe abortion [4]. A retrospective medical chart review of all gynecological cases was done at four large public hospitals in Nepal from 2001 to 2010; all cases of spontaneous and induced abortion complications were identified. Among all abortion cases, 23,493 cases of abortion complications identified [5]. The amendment of Muluki Ain (Civil Service Act) in September

(C) The Author(s). 2019 Open Access This article is distributed under the terms of the Creative Commons Attribution 4.0 International License (http://creativecommons.org/licenses/by/4.0/), which permits unrestricted use, distribution, and 
2002 declared abortion as legal. Within this law, the woman can decide abortion on her own if she wished up to twelve weeks of conception, and up to eighteen weeks following a rape or incest. When the continuation of pregnancy possesses a serious threat to mother and if there is a major fetal congenital malformation incompatible with life, abortion can be done [6].

A range of providers, including nurses and midwives, have been shown to be competent to deliver abortion services safely in a number of settings. As with many other medical procedures, adherence to best practice standards ensures that the most effective and safest services are delivered in a respectful and sensitive manner that recognizes women as decision maker [7]. A randomized control trial in South Africa and Vietnam showed that the training of the mid-level service providers such as nurses to provide safe abortion services is the key for improving access. Study have shown that mid-level providers can provide Post Abortion Care (PAC) equally safely and effectively as physicians $[8,9]$. To reduce the country's high maternal mortality rate, access to safe abortion services has a high significance. Creating an enabling environment for women in the community and health facility to access the CAC services is crucial to reduce unsafe abortion in Nepal. The national safe abortion policy has been progressively implemented since CAC service was started first at Maternity Hospital, Kathmandu, Nepal in March 2004. According to the procedural order, both service providers and facilities must be approved and the policy sets out provision that both provider and facility must be registered with certificate of competency by concerned authority [10]. The elements of CAC are high quality abortion care service that women have access to and affordable in the communities where they live and work which includes contraception, post abortion care and pain management [11-13]. The World Health Organization (WHO) has recommended medical abortion, manual vacuum aspiration and dilatation and evacuation as safe methods of abortion. Similarly, the WHO clinical practice handbook for safe abortion also emphasizes about the provider's awareness of local laws and reporting requirements within the national framework including all norms, standards and clinical practice related to abortion care. The provider should also possess the stated clinical skills to confirm diagnosis of pregnancy and preconditions of women to pursue termination of pregnancy and intervention method with the informed and voluntary decision making by the woman; nondiscrimination, confidentiality and privacy must be maintained [14]. The Who guideline on health role in providing safe abortion care and post abortion contraceptives states that a wide range of health care providers beyond the specialist doctors is an increasingly important public health strategy. The task shifting and sharing ensure a rational optimization of available health workforce to address shortages of specialized health care professionals, improve equity in access to health care and increase the acceptability of health services for those receiving them by utilizing Nurses, Auxiliary Nurse Midwives (ANMs) and complementary health care providers with necessary training [15]. Another study among 100 patients in Kathmandu Medical College Hospital (KMCH), Nepal, who received CAC services found that the major reason for abortion was no desire for more children $(60 \%)$ followed by younger child or short interval in pregnancy (21\%) [16].

\section{Methods}

\section{Study setting}

Tribhuvan University Teaching Hospital (TUTH) is a tertiary level referral teaching hospital situated in Maharajgunj, in the middle of Kathmandu, Nepal, as a part of Institute of Medicine, Tribhuvan University. There are twenty-eight departments in the hospital including Nursing, Dental, and Allied health sciences along with medical fraternity. Among specialty department, the Obstetrics and Gynecology department has the highest patient throughput in the hospital. Since 2006 CAC service was introduced in TUTH, family planning clinic as a part of government policy to expand CAC services in all health sectors. Since then the CAC service was provided here through trained doctor and Nurses.

Therefore, this study was done with the objectives to identify the trend of CAC service delivery, client characteristics, category of service providers, and reasons for seeking CAC services, its effectiveness and complications. This study was done to bring useful information to advocate for more involvement of nurses as CAC provider and scale up efforts to train nurses to provide quality CAC services.

\section{CAC procedure performed in the family planning clinic in the hospital}

Standard CAC service is provided to those women who missed their menstrual period and seeking CAC service. The standard CAC service consists of counseling of the woman, then record of history, conduct physical and per vaginal examination at the time of visit. Prior to CAC service prophylactic antibiotic and analgesia (Doxycycline $100 \mathrm{mg}$ and Ibuprofen $400 \mathrm{mg}$ ) used to be given half an hour before the procedure. Anesthesia is also given with $1 \%$ xylocaine Para cervical block. Manual Vacuum Aspiration (MVA) of the uterus is performed as described in standard techniques. After 1-2 h of observation, the woman is discharged with her choice of contraception (or contraception supplied to her) ${ }^{.11}$. 


\section{Data collection and analysis}

A retrospective review of CAC register was carried in Family Planning and CAC center of TUTH, Kathmandu starting from the period of inception, March 2006 until the end of March 2015 with the approval from the nursing department. The register of CAC service in the Family Planning and CAC center was explored for data collection. As the data were collected from the records, only variables available in the register could be analyzed. This include, name, age, gravid, parity, area of living, week of gestation, method of CAC procedure, CAC service provider, outcome of CAC procedure, complications and remarks. The information were first entered in the excel program and then transferred to SPSS software version 20, which was used for the analysis. Qualitative data included the reasons for abortion, complications which were analyzed manually.

\section{Ethical approval}

Ethical approval (Ref no-37(6-11E) [2] /073-074) was obtained from the Institutional Review Board of Institute of Medicine, Tribhuvan University to conduct the study and publication of the manuscript. Since it was a retrospective review of the available information in the patient registry, individual participant's consent was not applicable. Permission letter was also obtained from the TUTH for the publication of manuscript.

\section{Results}

In total, there were 2367 women who received CAC services in the TUTH in ten years period. The women's age ranged from 14 years to 53 years and the mean age was 28.4 years $(\mathrm{SD}=5.8)$. The majority of women $(54 \%)$ were young adults of age 20-29 years. Regarding the level of education the highest proportion (34\%) had secondary level education while only (4.6\%) had masters level. Similarly, $70 \%$ of the women were house wives, $56.2 \%$ were non classified ethnic group (Brahmin, Chhetris, Thakuri, Sanyasi Marwadi etc., Health Management Information System (HMIS)-11) who are considered as educated rich and upper class in the social system and $88.8 \%$ were from the Kathmandu valley. The majority (98.9\%) of the women were married (Table 1 ).

\section{Reproductive health status of CAC users}

Reproductive health status of women showed multi gravid $84 \%$ while $16 \%$ were primi gravid. Similarly, parity of women showed $63 \%$ were multi para. The gestational week of conception varied from 5 to 12 weeks. Eighty six percent of women had MVA as method of abortion and $14 \%$ had medical abortion. Regarding the post abortion contraception, only $37.6 \%$ women used any method,
Table 1 Demographic characteristics of CAC service users

\begin{tabular}{|c|c|c|}
\hline Variables & Number & Percent \\
\hline \multicolumn{3}{|l|}{ Age $(n=2357)$} \\
\hline 14-19 years & 94 & 4 \\
\hline 20-29 years & 1284 & 54.2 \\
\hline 30-39 years & 876 & 37.2 \\
\hline $40-49+$ years & 106 & 4.4 \\
\hline \multicolumn{3}{|l|}{ Education ( $n=2315$ ) } \\
\hline Illiterate & 358 & 14 \\
\hline Literate & 546 & 25.4 \\
\hline Basic (ECD- grade8) & 165 & 7 \\
\hline Secondary [9-12] & 788 & 34 \\
\hline Bachelor & 350 & 15 \\
\hline Master & 108 & 4.6 \\
\hline \multicolumn{3}{|l|}{ Occupation ( $n=2309$ ) } \\
\hline Housewife & 1637 & 70.8 \\
\hline Agriculture & 6 & 0.2 \\
\hline Service & 397 & 17 \\
\hline Student & 146 & 6.5 \\
\hline Own business & 123 & 5.5 \\
\hline \multicolumn{3}{|l|}{ Ethnicity $(n=2163)$} \\
\hline Hill Dalit (1a) & 17 & 0.8 \\
\hline Terai Dalit (1b) & 9 & 0.4 \\
\hline Disadvantaged Hill Janajati (2a) & 342 & 16 \\
\hline Disadvantaged TeraiJanajati (2b) & 129 & 6 \\
\hline Disadvantaged non-dalitgroup [3] & 44 & 2.0 \\
\hline Religious minority [4] & 13 & 0.6 \\
\hline Relatively advantaged Janajati [5] & 382 & 18 \\
\hline $\begin{array}{l}\text { Non-classified ethnic groups [6] } \\
\text { (Brahmin, Chhetris, Thakuri, Sanyasi } \\
\text { Marwadi etc., HMIS-11) }\end{array}$ & 1218 & 56.2 \\
\hline \multicolumn{3}{|l|}{ Residence of CACusers ( $n=2266$ ) } \\
\hline Inside Kathmandu & 2013 & 88.8 \\
\hline Outside Kathmandu & 253 & 11.2 \\
\hline \multicolumn{3}{|l|}{ Maritalstatus $(n=2367)$} \\
\hline Married & 2342 & 98.9 \\
\hline Unmarried & 25 & 1.1 \\
\hline
\end{tabular}

among them, the 29\%, used Intra Uterine Device (IUD) followed by Depo-Provera 28\% (Table 2).

\section{Service provider and reasons for seeking CAC}

More than half of the CAC service providers in TUTH were doctors. The reason for using the CAC services were completed family (55\%) among multi parous women, unwanted pregnancy (33\%), socioeconomic (includes financial problem, family problem, small child, rape, and husband left) along with other problems (8\%) (Fig. 1). 
Table 2 Reproductive health status of CAC users

\begin{tabular}{lll}
\hline Variable description & Number & Percent (\%) \\
\hline Gravid $(n=2354)$ & 381 & 16 \\
Primi & 1973 & 84 \\
Multi & & \\
Para ( $n=1945)$ & 717 & 37 \\
Primi & 1228 & 63 \\
Multi & & \\
Gestational Weeks ( $n=2367)$ & 2098 & 88.6 \\
5- 8 weeks & 269 & 11.4 \\
9-12 weeks & & \\
Procedure of CAC ( $n=2367)$ & 2027 & 85.6 \\
Manual Vacuum Aspiration(MVA) & 340 & 14.4 \\
Medical abortion [7] & & \\
Used post CAC contraception ( $n=894)$ & 258 & 29 \\
IUD & 253 & 28 \\
Depo & 132 & 15 \\
Oral contraceptive Pills & 22 & 2 \\
Norplant & 18 & 2 \\
Natural method & 125 & 14 \\
Condom & 44 & 5 \\
Plan for Non Scalpel Vasectomy & & \\
\hline
\end{tabular}

\section{Trends of CAC services in TUTH}

The trend of CAC service delivery in ten years from 2006 to 2015 showed mostly similar patterns except in the first year 2006, there was 40 cases only as it was the beginning of service year only few months was covered. In following years the CAC service pattern ranged from 275 to 272 cases per year. In 2015 the CAC service significantly reduced to 189 cases only compared to previous years (Fig. 2).
Providers and procedures used in CAC service

In the initial period of introduction of the CAC service, it was provided by doctors only and nurses were trained as assistants. Later, nurses were also trained as provider of CAC service for dealing with pregnancies up to eight weeks gestation period. Doctors provided 62\% $(n=1478)$ CAC services out of which 1281 was Manual Vacuum Aspiration (MVA) and 197 was Medical abortion (MA). Nurses provided 38\% $(n=889)$ CAC services and out of which 746 was MVA and 143 was MA (Fig. 3).

\section{Complications of CAC services at TUTH}

Overall incidence of complications of CAC services was $1.8 \%$. The commonest complication was incomplete abortion representing $1.4 \%$ which was again intervened with Post Abortion Care procedure (PAC). Six women had bleeding complications which was treated with ringer's lactate IV fluid and other measures such as rest and observation and misoprostol 4 tabs. Vaginal insertion in follow up. Three women complained abdominal pain and were managed with pain medication. One woman got continuation of pregnancy which was identified in the follow-up. Regarding the rate of complications among the service providers, it showed that the rate of CAC complications was $2.4 \%$ among doctors and $0.8 \%$ among nurse providers (Fig. 4).

\section{Discussions}

The trend of CAC service delivery in ten years from 2006 to 2015 showed a similar pattern in different years. In 2015 the CAC service significantly reduced to 189 cases. This may be due to great earthquake in the year 2015 when client attendance and movement was limited in the CAC center or they were seeking CAC service from the other nearby CAC delivery sites to them.

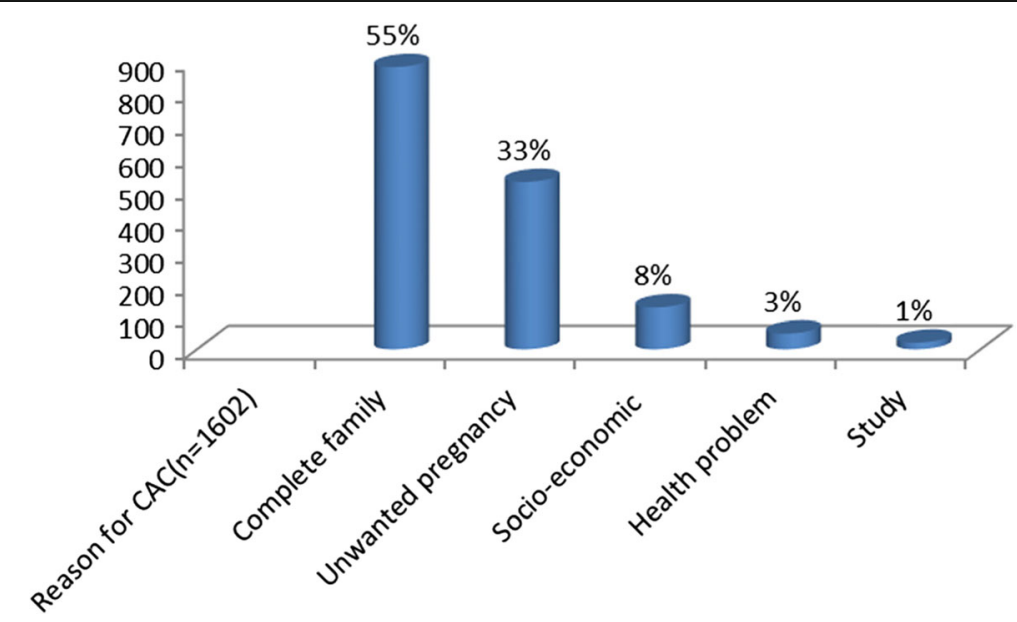

Fig. 1 Reasons for using Comprehensive Abortion Care services 


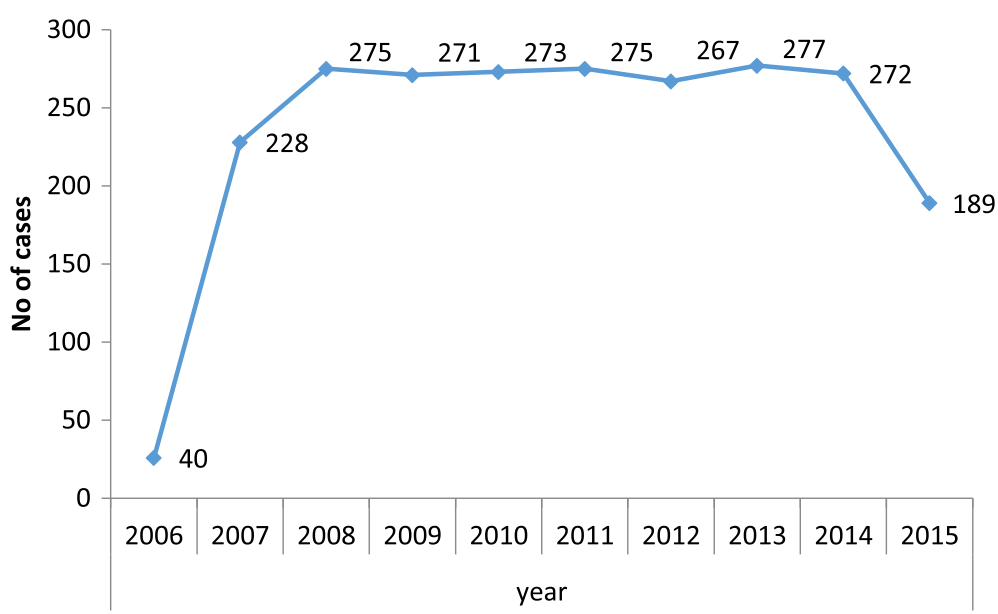

Fig. 2 Trend of CAC in TUTH 2006-2015 AD

Reproductive health status of women who used CAC service showed multi gravid $84 \%$ while $16 \%$ were primi gravid. And the parity of women showed $63 \%$ were multi para.

Eighty-six percent of women had MVA as method of abortion and $14 \%$ had medical abortion who seeks CAC services. This showed the high prevalence of unwanted pregnancy among the married women which needs to be addressed with appropriate family planning (FP) counseling. A retrospective study in CAC and PAC center of a maternity hospital in Nepal showed that the major reason for seeking abortion was too many children (59\%) followed by illegitimate pregnancy (16\%) [15]. However, this study showed the reason for seeking CAC was completed family (55\%) followed by unwanted pregnancy (33\%). Regarding the contraceptive devices used by women, previous study showed that contraceptive acceptance rate was $90 \%$ [16], however it was only $38 \%$ in this study. This finding is an indicator that much greater efforts are needed to increase the delivery of contraception to women immediately following the abortion procedure. Although CAC was safe in majority of women, some women were found to have complications. Thus an unwanted pregnancy must be avoided rather than being exposed to the risks of abortion.

A study done at southern general hospital, Glasgow, UK, found that $12 \%$ of abortion recipients' were adolescents among them 18-19 years of age accounted for $8 \%$ and $15-17$ years of age was $3 \%$ and those younger than 15 years of age was $0.2 \%$ in 2014 [17]. However, only $4 \%$ of women were adolescents in this study. Regarding the complications of CAC, this study showed that the overall prevalence was $1.8 \%$. The commonest complication was incomplete abortion (1.4\%); six women had bleeding complications and three women complained abdominal pain which were comparatively lower than the reports of other studies. In other settings of low resource countries the complication rate of incomplete abortion was $1.3 \%$ which was higher than expected range of $0.5-1.2 \%$ [18]. Thus, it is suggested to develop provision of adequate training to providers for ensuring the complete removal of retained product of conception (RPOC) after the CAC procedure. Likewise, to aid in expulsion of small fragments of RPOC not removed during the procedure,

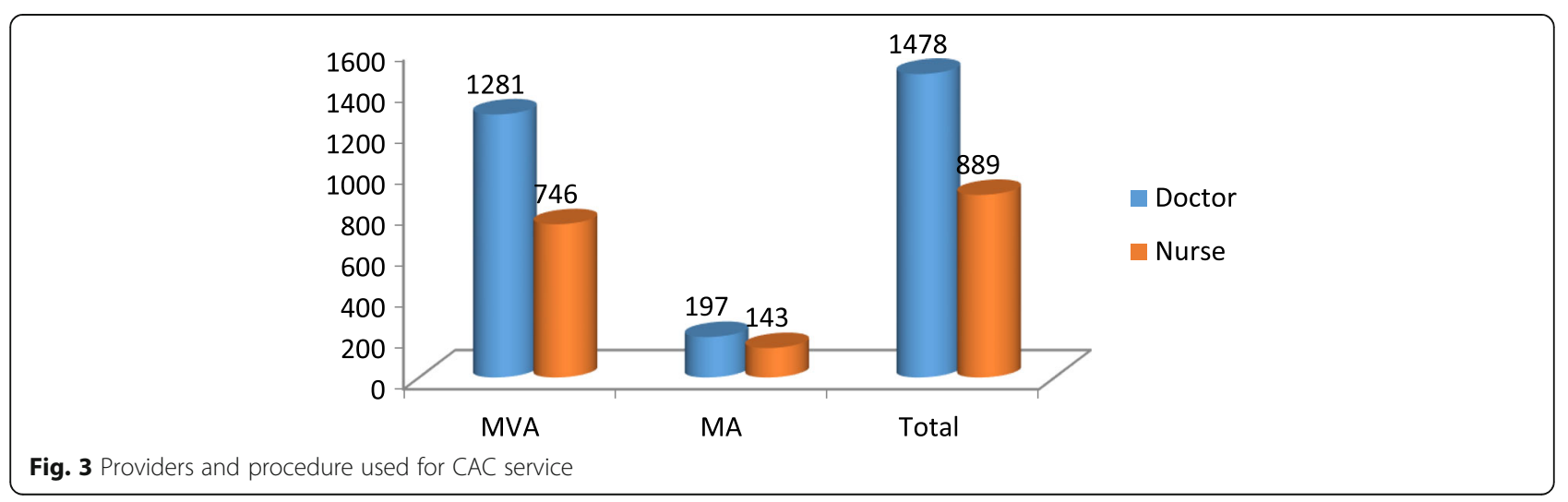




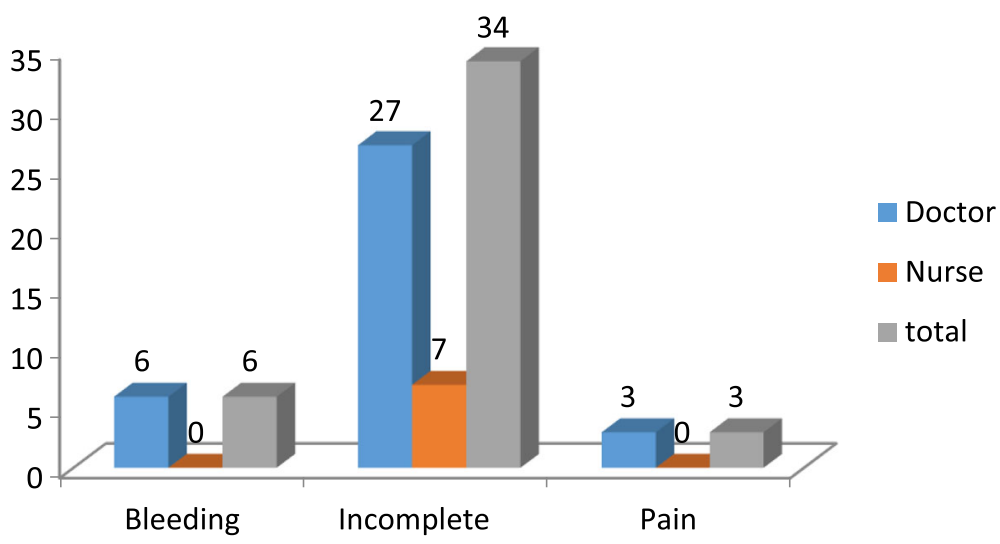

Fig. 4 Complications of CAC Procedure

administration of oxytocin, should be made as a rule [19]. Similarly, use of transvaginal ultrasound after the CAC procedure may help in determining whether products of conception remain in uterus or not $[20,21]$.

Similarly regarding the rate of complications among the service providers it showed that the rate of CAC complications was $2.4 \%$ among doctor providers and $0.8 \%$ among nurse providers. This showed that nurses are equally competent to the doctors in this study. This may be because nurses performed CAC only up to 8 weeks pregnancy while doctors do up to twelve weeks of pregnancy. This may be further influenced by the fact that the doctors were resident trainees in the most of the cases. In this regard a study result from Maternity hospital at Kathmandu showed that $1.6 \%(n=68)$ of women who had surgical abortion and $1.2 \%(n=12)$ of women who had medical abortion women had experienced complications, the overall complication rate being1.4\% [22]. Clients preferred nurses to physicians by $67 \%$. Nurses and facility managers pointed out a need for additional support, including further training and improve drug and equipment supply [19]. To maintain service quality for effective abortion care there should be a provision of continuous service improvement strategies to meet the need and rights of women [23]. Substandard service quality results in low acceptability of legal abortion services that may lead women to seek unqualified providers to perform self-induced abortions. This may result in abortion-related morbidity and mortality [20, 21]. The result of a multicenter randomized controlled equivalence trial done in five rural district hospitals in Nepal stated that the provision of medical abortion up to 9 weeks' gestation by mid level providers (staff nurses (3-year degree) and auxiliary nurse midwives) and doctors was similar in safety and effectiveness. Appropriately trained midlevel health-care providers can provide safe, low-technology medical abortion services for women independently from doctors. A systematic review concluded that the medical termination of pregnancy (TOP) and medical treatment of incomplete miscarriage performed by trained non doctor providers in the first trimester is probably as safe as treatment provided by doctors. They also concluded that women were equally satisfied with their providers regardless of who treats or manages their medical TOP $[24,25]$.

The current study was done with limited data available in the CAC register so could not analyze variables which were done in reference studies.

\section{Conclusions}

The trend of CAC service use in TUTH is nearly constant in ten years period except some decline in the year 2015. The major reason for undergoing CAC service was unwanted pregnancy. This is not a rigorous scientific comparison of complication rates for doctors and nurses and therefore could not draw the conclusion that nurses perform CAC as safely as doctors. This is an observational retrospective study that identified a lower complication rate for nurses than doctors. Additional training and supply of drug and equipment are needed to strengthen CAC service and ensure that nurses are able to continue providing high quality care. Training of nurses should be scaled up to expand CAC service provision across Nepal.

\section{Abbreviations}

ANMs: Auxiliary Nurse Midwives; CAC: Comprehensive Abortion Care: FP: Family Planning; HMIS: Health Management Information System; IOM: Institute of Medicine; KMCH: Kathmandu Medical College Hospital; MA: Medical Abortion; MVA: Manual Vacuum Aspiration; PAC: Post Abortion Care; RPOC: Retained Product of Conception; SPSS: Statistical package for Social Science; TOP: Termination of Pregnancy; TUTH: Tribhuvan University Teaching Hospital; WHO: World Health Organization

\section{Acknowledgements}

The author like to express gratitude to the authority of Tribhuvan University Institute of Medicine, Institutional Review Board, Tribhuvan University Teaching Hospital, Hospital Director, Nursing Director, Head of Department 
Gynea and obstetrics department, Incharge and Staff of Family Planning and CAC Center, data collection and entry staff.

\section{Funding}

No funding was available for this study. All work was done for the author's personal interest and effort.

\section{Availability of data and materials}

The datasets generated and analyzed during the current study are not publicly available due to hospital policy.

\section{Authors' contributions}

JTS has contributed to design retrospective data collection format from the Comprehensive Abortion Care registry of Tribhuvan University Teaching Hospital. The data collection was done in guidance of author by a data collection assistant. The data were entered in the SPSS program by the data collection assistant. The cleaning, verification of data entry, data analysis, and manuscript writing was done by the author.

\section{Ethics approval and consent to participate}

Ethical approval (Ref no-37(6-11E) [2] /073-074) was obtained from the Institutional Review Board of Institute of Medicine, Tribhuvan University to conduct the study and publication of the manuscript. Since it was a retrospective review of the available information in the patient registry, individual participant's consent was not applicable.

\section{Consent for publication}

Not applicable.

\section{Competing interests}

The authors declare that they have no competing interests.

\section{Publisher's Note}

Springer Nature remains neutral with regard to jurisdictional claims in published maps and institutional affiliations.

Received: 22 June 2017 Accepted: 21 February 2019

Published online: 28 February 2019

\section{References}

1. Ganatra B, Gerdts C, Rossier C, Johnson BR Jr, Tunçalp Ö, Assifi A, et al. Global, regional, and subregional classification of abortions by safety, 201014: estimates from a Bayesian hierarchical model. Lancet. 2017;390(10110): 2372-81.

2. Crehpa and Guttmacher Institute. Abortion and Unintended Pregnancy in Nepal. 2017 [cited 2018/07/13]; Available from: https://www.guttmacher. org/fact-sheet/abortion-unintended-pregnancy-in-nepal.

3. Puri M, Singh S, Sundaram A, Hussain R, Tamang A, Crowell M. Abortion incidence and unintended pregnancy in Nepal. Int Perspect Sex Reprod Health. 2016;42(4):197.

4. Bhadari T, Dangal G. Maternal mortality: paradigm shift in Nepal. Nepal Journal of Obstetrics and gynaecology. 2012;7(2):3-8

5. Henderson JT, Puri M, Blum M, Harper CC, Rana A, Gurung G, et al. Effects of abortion legalization in Nepal, 2001-2010. PLoS One. 2013:8(5):e64775.

6. Sharma S. Legalization of abortion in Nepal: the way forward. Kathmandu University Medical Journal. 2004;2(1):1-2.

7. Royal College of Obstetricians and Gynaecologists. Best practice in comprehensive abortion care. Best Practice Paper No. 2. 2015; Available from: https://www.rcog.org.uk/globalassets/documents/guidelines/bestpractice-papers/best-practice-paper-2.pdf.

8. Basnet I, Clapham S, Shakya G, McCall M. Evolution of the postabortion care program in Nepal: the contribution of a national safe motherhood project. Int J Gynecol Obstet. 2004;86(1):98-108

9. Warriner IK, Meirik O, Hoffman M, Morroni C, Harries J, Huong NM, et al. Rates of complication in first-trimester manual vacuum aspiration abortion done by doctors and mid-level providers in South Africa and Vietnam: a randomised controlled equivalence trial. Lancet. 2006:368(9551):1965-72.

10. Ministry of Health and Population, Ipas, Crehpa. Nepal Comprehensive Abortion Care (CAC) National Facility-based Abortion Study 2006. 2007: Available from: http://library.nhrc.gov.np:8080/nhrc/handle/123456789/196.
11. Engender Health, Ipas. COPE ${ }^{\oplus}$ for Comprehensive Abortion Care A Toolbook to Accompany the COPE ${ }^{\circledR}$ Handbook. 2009; Available from: https://www. engenderhealth.org/files/pubs/qi/cope-for-abortion-care.pdf.

12. Ipas. Comprehensive Abortion care/Elements of comprehensive abortion care. Available from: http://www.ipas.org/en/What-We-Do/ComprehensiveAbortion-Care/Elements-of-Comprehensive-Abortion-Care.aspx.

13. Prata N, Bell S, Gessessew A. Comprehensive abortion care: evidence of improvements in hospital-level indicators in Tigray, Ethiopia. BMJ Open 2013;3(7):e002873.

14. World Health Organization. Clinical practice handbook for safe abortion: World Health Organization; 2014

15. World Health Organization. Health worker role in providing safe abortion care and post abortion contraception: World Health Organization; 2015.

16. Saha R, Shrestha N, Koirala B, Kandel P, Shrestha S. Patients choice for method of early abortion among comprehensive abortion care (CAC) clients at Kathmandu medical college teaching hospital (KMCTH). Kathmandu Univ Med J (KUMJ). 2007:5(3):324-9.

17. Harvey N, Gaudoin M. Teenagers requesting pregnancy termination are no less responsible about contraceptive use at the time of conception than older women. BJOG Int J Obstet Gynaecol. 2007:114(2):226-9.

18. Thapa S, Satyal I, Malla K. Safe abortion service and post abortion care: understanding complications. Nepal Journal of Obstetrics and gynaecology. 2007;2(1):44-9.

19. Pande S, Sharma M, Saha R, Thapa M, Shrestha N, Regmi D. Comprehensive abortion care service at Kathmandu medical college-an experience. Kathmandu University medical journal (KUMJ). 2005:3(3):225-9.

20. Basnett I, Shrestha M, Shah M, Pearson E, Thapa K, Andersen K. Evaluation of nurse providers of comprehensive abortion care using MVA in Nepal. J Nepal Health Res Counc. 2012;10(1):5-9.

21. Billings DL, Velásquez JF, Pérez-Cuevas R. Comparing the quality of three models of postabortion care in public hospitals in Mexico City. Int Fam Plan Perspect. 2003:112-20

22. Jerman J, Jones RK, Onda T. Characteristics of US abortion patients in 2014 and changes since 2008. New York: Guttmacher Institute; 2016

23. Westfall JM, Sophocles A, Burggraf H, Ellis S. Manual vacuum aspiration for first-trimester abortion. Arch Fam Med. 1998;7(6):559

24. Sjöström S, Dragoman M, Fønhus M, Ganatra B, Gemzell-Danielsson K. Effectiveness, safety, and acceptability of first-trimester medical termination of pregnancy performed by non-doctor providers: a systematic review. BJOG Int J Obstet Gynaecol. 2017;124(13):1928-40.

25. Warriner I, Wang D, Huong NM, Thapa K, Tamang A, Shah I, et al. Can midlevel health-care providers administer early medical abortion as safely and effectively as doctors? A randomised controlled equivalence trial in Nepal. Lancet. 2011:377(9772):1155-61.

Ready to submit your research? Choose BMC and benefit from:

- fast, convenient online submission

- thorough peer review by experienced researchers in your field

- rapid publication on acceptance

- support for research data, including large and complex data types

- gold Open Access which fosters wider collaboration and increased citations

- maximum visibility for your research: over $100 \mathrm{M}$ website views per year

At BMC, research is always in progress.

Learn more biomedcentral.com/submissions 